\title{
A experiência de autores judeus da psicologia sobreviventes do holocausto
}

\section{The Experience of Psychology Jews Authors Holocaust Survivors}

\author{
Milena Callegari Cosentino* \\ Universidade de São Paulo - USP, São Paulo, São Paulo, Brasil \\ Marina Massimi** \\ Universidade de São Paulo - USP, São Paulo, São Paulo, Brasil
}

\begin{abstract}
RESUMO
O objetivo desta pesquisa foi o de abordar o tema "trauma e memória" na literatura de autores judeus da Psicologia, que viveram na Europa no período da Segunda Guerra Mundial/Holocausto e analisar possíveis repercussões do trauma em suas vidas e teorias. O trauma psicológico é relacionado à vida de todo ser humano e tem merecido maior atenção de diversas disciplinas. Violência, catástrofes e más condições de vida afetam a vida de muitos direta e indiretamente. Os autores escolhidos foram Kurt Lewin, Viktor Frankl e Bruno Bettelheim. Utilizou-se o método historiográfico, especificamente da área de história da psicologia. Os resultados apontaram que a situação traumática vivida modificou a maneira se posicionarem na teoria elaborada e na vida. Nos relatos encontram-se recursos pessoais, de teor psicológico e cultural, utilizados para vivenciar ou superar o trauma. Em suma, existe uma significativa relação dos estudos por eles realizados com a vivência do trauma.

Palavras-chave: trauma psicológico, Holocausto, Kurt Lewin, Viktor Frankl, Bruno Bettelheim.
\end{abstract}

\begin{abstract}
The aims of this research were: to approach the theme "trauma and memory" in Psychology author's literature, who were Jews and lived in Europe at Second World War and Holocaust period, and to analyze the possible trauma's influence in their lives and theory. The psychological trauma is related to the life of every human and has received increasing attention from various disciplines. Violence, disasters and poor living conditions affect many people directly and indirectly. The authors chosen were Kurt Lewin, Viktor Frankl and Bruno Bettelheim. The method utilized is historiographyc, of history psychology area. The results indicated that lived traumatic situation changed the way they elaborate themselves in the developed theory and life. In those author's reports and articles, psychological, cultural and their own resources were used to experience and overcome trauma; in conclusion, there is a significant relationship between their studies and the trauma's experience. (CNPq/CAPES/FAPESP)

Keywords: psychological trauma, Holocaust, Kurt Lewin, Viktor Frankl, Bruno Bettelheim.
\end{abstract}




\section{Introdução}

Tomamos como principal objetivo deste trabalho verificar, na literatura PSI, o tema trauma e memória, a fim de analisar as possíveis repercussões da vivência traumática na vida de autores judeus, os quais participaram de situações potencialmente traumáticas. Trabalhamos especificamente com três autores da Psicologia (científica e filosófica), os quais viveram na Europa no século XX, em que ocorreram diversas situações traumáticas de maneira geral, especialmente no que se refere a Segunda Guerra Mundial e o holocausto, são eles: Viktor Frankl, Kurt Lewin e Bruno Betthelheim.

Este trabalho é de caráter historiográfico e, portanto, alocado na área de história da psicologia. Entre as possibilidades de se estudar a história da psicologia científica ou moderna, Massimi, Campos e Brožek (1996) descrevem cinco abordagens:

1. a abordagem biográfica: baseada na reconstrução da história de vida dos cientistas;

2. a abordagem descritiva e analítica: baseada na reconstrução dos acontecimentos históricos a partir do levantamento de fontes primárias e na busca da compreensão de cada elemento do fato histórico no seio de seu contexto de produção;

3. a abordagem quantitativa: que aplica a análise historiométrica à literatura psicológica;

4. a abordagem da história social: que enfatiza a primazia dos fatores sociais para explicar a evolução da psicologia cientifica e

5. o enfoque sociopsicológico, que busca combinar a primeira e a quarta abordagens (p. 43).

O presente trabalho se trata do estudo de autores judeus contemporâneos da psicologia, os quais sofreram com o Holocausto. Assim, busca-se um enfoque sociológico atentando para a vida dos autores e também para a produção teórica dos mesmos na psicologia. Não é feito um estudo nem uma reconstrução da biografia dos autores, mas considera-se que os acontecimentos e fatores sociais da época da Segunda Guerra Mundial influenciaram de alguma forma em suas vidas, publicações e teorias científicas.

De acordo com Wertheimer (1998), realizar a pesquisa histórica em psicologia faz-se necessário para redescobrir grandes ideias do passado; concentrar nas questões realmente fundamentais e nos temas que originaram a disciplina da psicologia; e auxiliar na integração e organização de um campo amplo e diversificado. Para o autor, adotar uma perspectiva histórica aponta maturidade e permite aos pesquisadores em psicologia reconhecer quais são os fatores 
externos à ciência que podem estar influenciando a prática dos cientistas.

Realizamos leituras, recortes e análises de relatos e/ou amostras autobiográficas de Kurt Lewin, Viktor Frankl e Bruno Bettelheim, judeus e teóricos da Psicologia que viveram no período da Segunda Guerra Mundial, sendo dois deles vítimas dos campos de concentração nazistas. Os principais livros estudados para a apreensão deste conteúdo foram: "Em busca de sentido: um psicólogo no campo de concentração" (FRANKL, 1977/1991); "A Psicologia do Sentido da Vida" (Frankl, autora: XAUSA, 1986); "Problemas de Dinâmica de Grupo" (LEWIN, 1948); "Dinâmica e gênese dos grupos" (Lewin, autor: MAILHIOT, 1991) e "O Coração Informado: autonomia na era da massificação" (BETTELHEIM, 1985/1988).

Estes autores viveram situação traumática: ou foram presos ou fugiram e, consequentemente, as suas obras surgiram a partir de suas próprias experiências, com forte influência desta vivência traumática. De alguma forma eles modificaram seu modo de pensar pela experiência traumática, mudaram suas perspectivas, ou, no caso de Viktor Frankl, a experiência possibilitou que ele confirmasse a teoria elaborada anteriormente.

Além disso, realizamos um recorte temporal, ou seja, optou-se por estudar os autores que viveram no período da Segunda Guerra Mundial. No entanto, é interessante observar que Sigmund Freud (1856-1939), muito embora tenha escrito alguns textos no final de sua vida, nos quais se percebe a influência do momento histórico em que vivia(quando se mudou para a Inglaterra, período da perseguição nazista aos judeus), a sua principal produção foi em um período anterior a essa experiência, haja vista que Freud faleceu no inicio da Segunda Guerra Mundial, e o fato de ter sido perseguido não alterou a teoria que havia elaborado.

De inicio são apresentados os relatos mais detalhados extraídos da obra de cada um dos autores estudados, e mais adiante algumas características comuns na vida e na obra dos mesmos. Vale antecipar que todos eles nasceram na Europa, eram procedentes de famílias judias e estavam na Europa no período antecedente à Segunda Guerra Mundial, sofrendo com a perseguição anti-semita.

\section{Considerações sobre o trauma psíquico}

O trauma psíquico tem merecido uma atenção cada vez maior das mais diversas disciplinas, uma vez que desastres, violência, catástrofes e más condições de vida afetam a vida de muitos direta e indiretamente, graças à rapidez de informação. Os diagnósticos de Transtorno de Stress Pós-Traumático estão cada vez mais freqüentes, 
sendo que as características da vida atual no Ocidente são propícias para que traumas ocorram (RUDGE, 2009).

\title{
3 Algumas Definições de Trauma em Psicologia
}

Um evento traumático pode ser definido como uma situação em que há experiências relacionadas à morte ou perigo de morte, lesões significativas ou risco para a integridade do indivíduo que o vivencia e/ou de outras pessoas, quando a resposta da vítima envolve medo intenso, horror ou sensação de impotência (GUERREIRO; BRITO; BAPTISTA; GALVÃO, 2007).

A partir disso, tem-se que o trauma psicológico se dá pelo impacto crítico e extremo causado por um estressor no funcionamento psicológico ou biológico de um indivíduo. Alguns exemplos comuns de eventos traumáticos para indivíduos e/ou famílias são situações de combate, raptos, atos de terrorismo, desastres naturais e humanos, homicídios, assaltos, violência física e sexual, acidentes de viação e doenças com risco de morte (GUERREIRO et al, 2007).

Diante de situações de elevada carga emocional, através de mecanismos de regressão, o funcionamento racional tende a ser substituído pelo funcionamento emocional (GUERREIRO et al, 2007). Ao que se pode observar, os comportamentos considerados adequados ao espaço e ao contexto social, são alterados para comportamentos associados à desorientação no tempo e no espaço, incapacidade para articular palavras ou frases complexas, choro, ou comportamentos orientados para a sobrevivência.

No Dicionário de Psicologia da APA (VANDERBOS, 2010), o trauma é definido como:

\begin{abstract}
Evento no qual uma pessoa testemunha ou vivencia uma ameaça a sua própria vida ou segurança física ou a de outros e experimenta medo, terror ou impotência. $O$ evento também pode causar dissociação, confusão e a perda da sensação de segurança. Eventos traumáticos desafiam a visão de mundo de um indivíduo como um lugar justo, seguro e previsível. Traumas causados por comportamento humano (p. ex., estupro, assalto, acidentes tóxicos) comumente têm mais impacto psicológico do que aqueles causados pela natureza (p. ex., terremotos) (p. 992).
\end{abstract}

Já o trauma psíquico é uma "experiência que inflige dano à psique, frequentemente de natureza duradoura. Exemplos são: estupro e abuso de criança" (VANDERBOS, 2010, p. 993).

De acordo com CANEPA \& CAMPOS (2003), Freud já falava sobre trauma de choque antes mesmo de outros autores: "Trauma é o 
resultado de uma ruptura da proteção contra as excitações do mundo exterior". Freud ainda dizia:

\begin{abstract}
Descrevemos como "traumáticas" quaisquer excitações provindas de fora que sejam suficientemente poderosas para atravessar o escudo protetor. Parece-me que o conceito de trauma implica necessariamente numa conexão desse tipo, com uma ruptura numa barreira sob outros aspectos eficaz contra os estímulos. Um acontecimento (externo) como um trauma está destinado a provocar um distúrbio em grande escala no funcionamento da energia do organismo e a colocar em movimento todas as medidas defensivas possíveis (FREUD, 1920, p. 40).
\end{abstract}

Assim, para Freud, o trauma seria "uma brecha na barreira protetora contra a estimulação levando a sentimentos avassaladores de impotência", ou seja, uma quebra da auto-regulação criativa e perda da resiliência do sistema nervoso (FREUD, 1919-1920, apud CANEPA; CAMPOS, 2003).

Para Charcot, o trauma é um choque acompanhado de emoções intensas e seus efeitos são ainda maiores em situações de esgotamento, quando o sistema nervoso estiver fragilizado por doenças ou outros fatores da vida (RUDGE, 2009).

Já Winnicott aborda o trauma na vida do indivíduo desde sua tenra infância, isto é, quando bebê e, para ele, o que se entende por trauma depende do momento em que a criança está no seu processo de crescimento, um crescimento que vai da dependência absoluta em direção à independência relativa, da primeira infância para maturidade plena. Ou seja, deve-se considerar os diversos sentidos do que se entende por trauma, referindo cada um deles a uma etapa do processo de amadurecimento (FULGENCIO, 2004). Winnicott acrescenta:

Um trauma é aquilo contra o que um indivíduo não possui
defesa organizada, de maneira que um estado de confusão
sobrevém, seguido talvez por uma reorganização de defesas,
defesas de um tipo mais primitivo do que as que eram
suficientemente boas antes da ocorrência do trauma.
(WINNICOTT, 1970b, p. 259; tr. p. 201 apud FULGENCIO,
2004, p. 264)

Jaspers evidencia que há uma repercussão do acontecimento traumático na vida do individuo devido à repetição e somação das vivências dessa situação, mesmo que os fatos de perturbação já tenham desaparecido:

O conceito de Reação Patológica tem uma parte compreensível (vivência e conteúdo), uma parte causal (alteração no extraconsciente) e uma parte de prognóstico 
(esta alteração é passageira). Ainda que possa ser anulada a momentânea transposição em um estado anormal (em especial depois do desaparecimento dos fatos de perturbação) produzindo-se a cura em seguida, existe sem dúvida uma repercussão graças à estreita ligação da vivência e personalidade pela repetição e somação das vivências... (JASPERS, 1977, apud FERREIRA-SANTOS et al, 2006, p. 2)

Não se pode ignorar que o trauma vivido pode gerar conseqüências negativas na vida do individuo e de seus descendentes, como medo, depressão, entre outras, por levar a crer que, como ocorreu a situação traumática vivenciada, sempre haverá possibilidades de acontecer algo semelhante novamente. Por outro lado, uma experiência traumática pode produzir efeitos positivos na vida do indivíduo, uma vez que este se encontra diante da possibilidade de desenvolver a capacidade de enfrentamento, de começar de novo, construir uma "nova história" a partir de determinado momento de sua vida. Além disso,

as representações do trauma para o sujeito vão variar conforme o destino que ele dê a essa experiência. À falta de sentido que preside o impacto do trauma geralmente se responde com a tentativa de construir narrativas que tornem o acontecimento menos gratuito (RUDGE, 2009, p. 67).

\section{Os Judeus e o Holocausto}

Vale ressaltar que exemplos de diversas possibilidades de posicionamentos não são encontrados apenas nas existências individuais, mas também na história e na memória dos povos. Dentre eles, o povo judeu apresenta uma história marcada por perseguições e vivências potencialmente traumáticas: tiveram 430 anos como escravos no Egito (séc.XX a séc.XVI a.C.), ficaram cativos na Assíria (séc. VIII a.C.), estiveram 70 anos no cativeiro Babilônico (séc.VI a.C.), ficaram sob o domínio dos Impérios Persa, Grego e Romano (do séc.V a.C. ao séc.I d.C.), sofreram a Diáspora (séc.I d.C.), o Holocausto (séc.XX d.C.), entre outras perseguições e prisões.

A Segunda Guerra Mundial (1939-1945), juntamente com o Holocausto, é um evento histórico que marcou a vida de muitas famílias, judias ou não. De acordo com Feldmann (2001), já em 1933 o terror conduzido pelo Estado alemão nazista era crescente: as tropas de choque nazistas batiam nos judeus na rua a ponto de precisarem ser levados para os hospitais; obrigaram os professores judeus a interromper suas atividades; colocavam placas nas casas para provar que ali não morava nenhum judeu; os médicos e os advogados judeus perdiam seus clientes; nas lojas as pessoas colocavam placas dizendo que os judeus não eram bem-vindos ali e 
até mesmo brinquedos para crianças tinham o nome de "fora judeus!"

O Holocausto mobilizou a sociedade da época e o mais profundo da vida judia, e até mesmo a religião judaica. Para se ter uma idéia, antes deste acontecimento, viviam na Polônia cerca de três milhões de judeus, dos quais restaram apenas cerca de seis mil. Nos demais países da Europa as proporções são mais ou menos semelhantes (BARRERA, 2005).

Mais especificamente, cerca de sete milhões e meio de pessoas perderam a dignidade e a vida nos campos de concentração, sendo a maioria judeus, mas também negros, ciganos, homossexuais, comunistas e portadores de doença mental. Estima-se que tenham sido mortos entre 5,1 e seis milhões de judeus na Segunda Guerra Mundial, o que representava $60 \%$ da população judaica na época. Os que eram condenados sofriam torturas, eram obrigados a fazer trabalhos forçados e acabavam morrendo por fome ou doença (GEOCITIES).

De acordo com Halbwachs (1968/2006), "Augusto Comte observou que o equilíbrio mental resulta em boa parte e antes de mais nada, no fato de que os objetos materiais com os quais estamos em contato diário não mudam ou mudam pouco e nos oferecem uma imagem de permanência e estabilidade" (p. 155), ou seja, o fato de muitos judeus terem sido presos em campos de concentração nazistas pode ter interferindo no equilíbrio mental ou na personalidade deles, visto que foi uma mudança brusca em suas vidas, ambientes e rotinas. $O$ autor acrescenta que:

quando algum acontecimento também obriga a que nos transportemos a um novo ambiente matéria, antes que a ele tenhamos nos adaptado, atravessamos um período de incerteza, como se houvéssemos deixado para trás toda a nossa personalidade: tanto isso é verdade, que as imagens habituais do mundo exterior são partes inseparáveis do nosso eu (HALBWACHS, 2006, p. 155).

\section{O pertencer e a Obra: A Influência Cultural na Obra de autores judeus}

De modo geral, o fato da história do povo judeu ter sido marcada por guerras e perseguições fez com que algumas características passassem a fazer parte de sua cultura, como a rememoração em festas das perseguições e dos "livramentos", a grande quantia de publicações referentes ao Holocausto e outras publicações das diversas áreas da ciência de autores judeus, que carregam de alguma forma a influência cultural da qual eles participam. 
No campo das Humanidades também há uma grande quantia de autores judeus. Por exemplo, Sigmund Freud (1856-1939), escreveu em "O mal-estar na civilização" (1930) para descrever a inata inclinação humana para a agressividade: "O Demônio seria a melhor saída como desculpa para Deus; desta maneira, ele estaria desempenhando o mesmo papel, como agente de descarga econômica, que o judeu desempenha no mundo ideal ariano" ( $p$. 124). Neste mesmo texto, ao explicar sobre "narcisismo das pequenas diferenças", Freud disse:

Com respeito a isso, o povo judeu, espalhado por toda parte, prestou os mais úteis serviços às civilizações dos países que os acolheram; infelizmente, porém, todos os massacres de judeus na Idade Média não bastaram para tornar o período mais pacífico e mais seguro para seus semelhantes cristãos (FREUD, 1930, p. 119)

Este autor, de tradição familiar judia, utilizava da cultura e do contexto dos quais fazia parte para explicar sua idéia ou teoria, mesmo não seguindo o judaísmo enquanto religião. Ele não se restringia apenas ao acontecimento contemporâneo a sua época, mas recorria a outros momentos da história de seu povo.

Em "Freud, leitor da Bíblia", Pfrimmer (1994) evidencia que a obra de Freud é repleta de citações bíblicas. Há cerca de quatrocentas citações, que na maioria das vezes aparecem de forma espontânea e sem introdução, parecendo fazer parte de sua bagagem cultural, se integrando no próprio texto. Além disso, Freud se identificava com alguns personagens bíblicos, por exemplo, José e Moisés.

Estes exemplos mostram a relação de Freud com o Judaísmo e as Escrituras, uma vez que, mesmo se dizendo ateu, ele apresentava uma influência cultural, por sua formação enquanto judeu.

Outro exemplo é Edith Stein (1891-1942): filósofa, assistente de Husserl e especialista na Fenomenologia da Psicologia. Diante de um momento de mudanças sociais e dos acontecimentos referentes ao nazismo, Stein, assim como outros judeus alemães, foi levada a refletir sobre si e seu destino e diante dessas reflexões propôs expor e defender a idéia do judaísmo contra as falsificações que muitos faziam (STEIN, 1985). Ou seja, em um momento de crise, Stein se voltou para a cultura de seus antepassados e, conseqüentemente, a sua, havendo um resgate de memórias e tradições.

Antes de ser presa, Stein escreveu um diário contando como era a vida de uma família judia, no intuito de mostrar a importância e o valor deste povo, diante das perseguições nazistas. Os judeus alemães de forma geral também tiveram uma experiência coletiva histórica, em que alguns se voltaram para as origens e tradições de seu povo. 
Ainda dentro das Humanidades, na área da Sociologia, Maurice Halbwachs (1877-1945), sociólogo durkheimiano e autor do livro "A Memória Coletiva" também era judeu. Ele apresentava sua visão teórica baseado também em sua experiência cultural, uma vez que para ele não é possível desvincular o indivíduo de seu grupo de pertença. Na introdução desta obra, Michel Alexandre escreveu que este livro foi publicado a partir dos papéis deixados por Halbwachs, 0 que traz fragmentos da grande obra que ele projetava sobre o tempo. As relações da memória e da sociedade haviam se tornado o centro e a baliza do seu pensamento. O autor foi preso pela Gestapo em 1944 e morto no campo de concentração de Buchenwald em 1945.

\begin{abstract}
Poderá parecer simbólico que um dos homens mais empenhados em definir a idéia do homem enquanto pessoa distinta das coisas, o que traz condenação radical do instrumento humano, do material humano, tenha passado pelo inferno dos campos de concentração, onde sociedade e indivíduo são negados e eliminados! (J.-MICHEL ALEXANDRE, In: HALBWACHS, 1986 , p. 23)
\end{abstract}

\title{
6 Resultados
}

\subsection{Viktor Frankl: Em Busca de Sentido.}

Viktor E. Frankl (1905-1997) nasceu em Viena, pertencia a uma família judia e foi educado dentro da tradição judaica; seus pais eram procedentes da Tchecoslováquia. Ainda jovem, teve contato com a psicanálise e aos 16 anos deu sua primeira palestra sobre "o sentido da vida". Em 1926 utilizou pela primeira vez o termo "Logoterapia". Em 1927 organizou centros de ajuda psicológica para jovens carentes de Viena. Especializou-se em neurologia nos anos de 1931 e 1932 e no período de 1933 a 1936 dirigiu o setor de mulheres suicidas no hospital psiquiátrico de Viena (XAUSA, 1986).

Em 1938 a Áustria foi ocupada por Hitler, e Frankl desistiu de ir para os Estados Unidos, pois seus pais eram idosos (XAUSA, 1986). Em dezembro de 1941 se casou e logo após, em 1942, ele, a esposa e toda a família foram levados para campos de concentração. Sua esperança sempre foi reencontrá-los, porém somente ele sobreviveu.

\subsection{Kurk Lewin: Problemas de Dinâmica de Grupo.}

Kurt Levin (1890-1947) nasceu em Mogilno, na Prússia. Era procedente de uma família judia. Em 1933 foi obrigado pelos nazistas a deixar a Alemanha em 24 horas, pagando um resgate para não ser preso em um campo de concentração. Após imigrar para os Estados Unidos, Lewin já de pronto dedicou sua atenção à psicologia de seu 
próprio grupo étnico, uma vez que as experiências que teve na Alemanha o traumatizaram sob muitos aspectos. Por ser judeu, sofreu discriminações, injustiças, vexames, ostracismo, entre outras situações. Assim, procurou compreender e encontrar uma interpretação cientifica para o que sofreu (MAILHIOT, 1991).

Começou explicando a "psicologia das minorias judias" (MAILHIOT, 1991, p. 29), então elaborou a "psicologia dos grupos minoritários" (idem), foi levado a repensar e a redefinir "que problemas constituem o centro da exploração e da experimentação da psicologia social?" (idem), o que resultou em sua obra "A dinâmica dos grupos" (idem). Os temas mais recorrentes em seu livro são: Problemas de Mudança Cultural; Conflitos em Grupos Primários; Conflitos Intergrupais e a Participação no Grupo: Problemas Psicológicos e Sociológicos de um Grupo Minoritário; Em face do Perigo; A Educação da Criança Judaica; O Ódio a Si Mesmo Entre os Judeus e Pesquisa de Ação e Problemas de Minoria (LEWIN, 1948).

\title{
6.3 Bruno Bettelheim: O Coração Informado
}

Bettelheim (1903-1990) nasceu em Viena. Era de família judia e psicólogo. Em 1938 foi detido pelos nazistas e enviado ao campo de concentração de Dachau e depois a Buchenwald. Depois de um ano mudou-se para os Estados Unidos, trabalhando como investigador, psicólogo e professor.

Bettelheim (1985) apresentou suas idéias sobre a condição do homem na sociedade moderna de massa e sobre o impacto psicológico das tendências totalitárias. Em uma tentativa de esboçar uma coerência interna ele incluiu um pouco de sua biografia e enfatizou que

\begin{abstract}
para neutralizar o impacto debilitador da sociedade de massa, a obra de um homem deve-se impregnar de sua personalidade (...) sua opção de trabalho (...) deve manifestar diretamente a maneira pela qual este homem busca sua auto-realização em nosso mundo [e] os resultados da obra (...) devem refletir os objetivos que ele próprio tem na vida (BETTELHEIM, 1985, p. 11 e 12).
\end{abstract}

\subsection{Recursos Utilizados Pelos Autores para Superar o Trauma e Teorias Elaboradas}

A teoria elaborada pelos autores foi uma resposta histórica dada ao sofrimento vivenciado, mas, ao mesmo tempo, eles chegaram a elementos sobre o humano e sobre a dinâmica do sofrimento, do trauma e a dinâmica da participação na história, o que é um passo novo para a Psicologia, uma vez que não se restringe apenas àquele momento histórico. 


\subsubsection{Victor Frankl}

Para Frankl o período vivido no campo de concentração foi como o experimentum crucis para suas idéias psicoterapêuticas (ROEHE, 2005). Ao se referir a esse tempo e a sua sobrevivência ele usava uma frase de Nietzsche, a qual repetiu em muitas de suas publicações: "quem tem por que viver agüenta quase todo como" (FRANKL, 1991, p. 75). Ali, Frankl perdeu seu manuscrito em que havia delineado os princípios da Logoterapia ("Terceira Escola Vienense de Psicoterapia") e, a princípio, deu por encerrada toda a sua vida intelectual.

No entanto, podem-se evidenciar alguns recursos pessoais utilizados por Frankl para enfrentar as situações adversas do campo de concentração, como, por exemplo, pensar no futuro e se enxergar em um momento posterior dando palestras sobre sua experiência. Do mesmo modo, o refúgio no passado também era uma forma de esquecer-se por um momento da situação atual de sofrimento e lembrar-se de experiências agradáveis. O humor também foi um recurso utilizado por Frankl, uma vez que Ihe possibilitava colocar-se acima das situações que estava vivendo. Por isso, combinou com um amigo de fazerem pelo menos uma piada por dia (FRANKL, 1991).

Encontrar sentido no sofrimento e até mesmo na morte o fortalecia a se posicionar diante das adversidades, buscando uma realização interna de valores. Frankl apontou que o sofrimento faz parte da vida, assim como o destino e a morte. Assinala que a liberdade espiritual do homem se baseia no fato de sempre, e em toda parte, a pessoa se colocar "diante da decisão de transformar a sua situação de mero sofrimento numa realização interna de valores" (FRANKL, 1991, p. 68), uma vez que "o sofrimento de certo modo deixa de ser sofrimento no instante que encontra um sentido" (FRANKL, 1991, p. 101). Assim, a pessoa tem a liberdade de escolher suas ações ao invés de simplesmente entregar-se e reproduzir o que as situações propiciam.

A partir de sua experiência, Frankl desenvolveu teorias e conceitos como, por exemplo, os "Valores de atitude", que surgem quando a pessoa está diante de uma situação limite de sofrimento inevitável. Com isso, enfatizava a importância do indivíduo se posicionar de forma a encontrar sentido nas dificuldades, uma vez que a busca de sentido é a principal força motivadora no ser humano (FRANKL, 1991). Para Frankl, o homem é insubstituível e tem uma responsabilidade por sua vida e pela continuidade da vida e a Logoterapia vê na responsabilidade a essência da existência humana, confrontando com a finitude da vida e com o caráter irrevogável do que a pessoa faz da vida e de si mesma. 
Deste modo, o sentido da vida sempre se modifica, mas jamais deixa de existir e pode ser afirmado de três formas diferentes: 1. Criando um trabalho ou praticando uma ação, 2. Experimentando algo ou encontrando alguém e 3 . Pela atitude que a pessoa toma em relação ao sofrimento inevitável, transformando a tragédia pessoal em triunfo (FRANKL, 1991).

Por fim, na Tese do Otimismo Trágico (pós-escrito em 1984), Frankl afirmou a possibilidade de a pessoa ser e permanecer otimista apesar da tríade trágica (dor, culpa e morte). Apresentou um otimismo diante da tragédia, tendo em vista o potencial humano de transformar o sofrimento numa conquista e numa realização humana, extrair da culpa a oportunidade de mudar a si mesmo para melhor e fazer da transitoriedade da vida um incentivo para realizar ações responsáveis.

\subsubsection{Kurt Lewin}

K. Lewin foi um autor importante da Psicologia social associada a dinâmica de grupos. Ele utilizou sua experiência enquanto judeu para tentar entender do ponto de vista psicológico o indivíduo associado a seu grupo de pertença e elaborou sua teoria a partir de suas vivências. Ao mesmo tempo, sua teoria o auxiliou a enxergar o problema da minoria judaica.

Lewin priorizava o estudo do tema do individuo no grupo, bem como da percepção que o mesmo tem dos fatos e da realidade. Para Lewin, a percepção que a pessoa tem dos acontecimentos é central para a maneira como ela organiza sua experiência e "o grupo a que pertence o indivíduo constitui a base de suas percepções, ações e sentimentos" (ALLPORT, G. W. In: LEWIN, 1948, p. 7).

Deste modo, é a base do grupo social que dá ao indivíduo sua configuração. A partir disso, Lewin discute a relação indivíduo-grupo e toda tensão que ser parte de um grupo representa.

O grupo é o solo, o território no qual o individuo se mantém, é o meio que o individuo participa e o espaço de vida do mesmo. Um dos objetivos vitais da pessoa é atingir ou manter determinada posição ou status dentro do grupo. E a dinâmica de valores e regras do grupo ao mesmo tempo que liberta, aprisiona (LEWIN, 1948).

Lewin (1948) sentia uma "necessidade de ação na vida judaica" ( $p$. 174) daquele momento em que os judeus estavam sendo destinados à tortura e destruição, pelo avanço do nazismo e fascismo. Isto porque, para ele, não havia indícios que a paz surgiria naturalmente nos anos seguintes e, portanto, era necessário que os judeus pensassem e agissem sobre aquela situação. Lewin afirmou que era necessário tratar o problema judeu cientificamente como um caso de minoria desprivilegiada, sendo que toda minoria desprivilegiada é mantida por uma maioria privilegiada. 
Os problemas de minorias na verdade também são problemas de maiorias e um grupo é considerado minoria psicológica quando seu destino coletivo depende da boa vontade de outro grupo. O grupo minoritário pode tanto tentar ser aceito e se incorporar ao grupo majoritário, como também se afastar e excluir, preservando suas características distintas. Um dos meios estratégicos para o aperfeiçoamento das relações intergrupais é a elevação do amor próprio dos grupos minoritários (LEWIN, 1948).

A partir disso pode-se compreender o ódio a si mesmo entre os judeus: é difícil para a pessoa se identificar como parte de um grupo, porque ao mesmo tempo que integra determinado grupo, faz parte de outros também. Assim, a mesma pode apresentar dificuldade para se definir enquanto indivíduo e ter um recorte de sua personalidade, por pertencer a diferentes grupos.

Além disso, pertencer ao grupo judeu implicava muitas vezes em situações ou experiências desagradáveis na sociedade. Portanto, é necessário que haja uma reeducação quando um indivíduo ou grupo "está fora de passo em relação à sociedade em geral" (LEWIN, 1948, p. 72). Para tanto, deve haver uma mudança na estrutura cognitiva, aceitação de novos valores e uma ação motora. Esta "reeducação só influencia a conduta quando o novo sistema de valores e crenças domina a percepção do indivíduo" (LEWIN, 1948, p. 84) e a aceitação desse novo sistema é ligada à aceitação de um grupo específico, de um determinado papel e/ou de uma fonte definida de autoridade como novos pontos de referência.

\subsubsection{Bruno Bettelheim}

Bettelheim escreveu "O Coração Informado" (1985) a partir de sua experiência e pôde perceber a influência do Estado totalitário nas sociedades de modo geral, o que compromete a autonomia e a preservação da personalidade do indivíduo. Sua obra tem um caráter abrangente: a partir da observação específica da realidade dos campos de concentração e do Estado Hitlerista, ele pôde ampliar este olhar para as sociedades contemporâneas de massa, tematizando a perda da autonomia e da espontaneidade das pessoas, na medida em que se acomodam ao que é oferecido ou "imposto" por esta sociedade, em troca de prazer e consumo.

Bettelheim pretendia entender este processo do ponto de vista psicológico e esta busca de conhecimento funcionava como uma defesa espontânea contra o impacto de uma situação extrema, em que ele usava de seus recursos (formação e educação específica) para defender-se de uma receada desintegração de personalidade. Seu principal cuidado no período que estava nos campos de concentração era proteger seu eu interior de forma que, se algum dia 
viesse a recuperar a liberdade, ele voltasse a ser a mesma pessoa que era quando a perdeu (BETTELHEIM, 1985).

Com sua experiência nos campos de concentração percebeu que 0 meio pode provocar transformações rápidas e profundas na personalidade do indivíduo. A partir disso, Bettelheim buscava alertar as pessoas acerca da ocorrência dos mecanismos de despersonalização na relação com o meio, pois os campos de concentração desenvolveram ao extremo técnicas para retirar do sujeito a iniciativa e levá-lo à perda da identidade, mas existem técnicas semelhantes, em menor grau, nas sociedades de massa contemporâneas (BETTELHEIM, 1985).

Para ele, o homem moderno sofre com a incapacidade de escolher entre renunciar a liberdade e o individualismo ou desistir dos confortos materiais da tecnologia moderna e a segurança de uma sociedade de massa coletiva. O ser humano vai se acostumado com as imposições do sistema e perde a reação espontânea diante da realidade e quanto mais precisa conter a espontaneidade ao reagir, mais fraca ela se torna, pelo desuso (BETTELHEIM, 1985).

Desta forma, a sociedade interfere na liberdade interna e externa do individuo, ameaçando sua autonomia. Sujeitar-se ao estado totalitário pode acarretar uma desintegração do que antes parecia uma personalidade bem integrada, além de um regresso a muitos comportamentos infantis, de obediência, dependência e submissão. Ao mesmo tempo, a personalidade pode se romper sob a pressão do Estado quando 0 indivíduo tenta resistir. $O$ objetivo do Estado totalitário é acabar com a individualidade e liberdade de ação, o foco deixa de ser o indivíduo e este e o grupo são forçados a mergulhar numa "massa geral maleável" (BETTELHEIM, 1985, 211). Os sujeitos em uma sociedade totalitária são despersonalizados e não há mais lugar para interesses pessoais.

A partir de sua experiência e das análises desta obra, o autor esperava ajudar as pessoas a decidir qual mudança desejariam operar em sua personalidade com o fim de se amoldarem melhor às exigências morais e emocionais, para poderem suportar as pressões de uma sociedade de massa, ou seja, que aprendessem como informar o coração em beneficio da autonomia (BETTELHEIM, 1985).

\section{Conclusão: Aprendendo e ensinado com a experiência}

As experiências e teorias dos autores apresentadas anteriormente estão relacionadas com o fato de pertencerem ao povo judeu e terem sofrido de alguma forma perseguição no período da Segunda Guerra Mundial por pertencerem a este grupo. Ao considerar o contexto sócio-histórico-cultural dos mesmos, são evidentes as influências dos 
fatores externos sobre suas teorias científicas (WERTHEIMER, 1998; MASSIMI; CAMPOS; BROŽEK, 1996).

Além disso, de alguma forma os autores sofreram trauma, pois enfrentaram perigo de morte, tiveram a vida e a segurança ameaçadas, ficando impotentes diante das situações encaradas (GUERREIRO et al, 2007; VANDERBOS, 2010).

Os três autores se refugiaram nos Estados Unidos. Frankl e Bettelheim foram presos campos de concentração, diferentemente de Lewin que fugiu para os Estados Unidos antes de ser preso. Ali eles tiveram liberdade para desenvolver suas teorias e suas obras foram baseadas na reflexão acerca do que sofreram nesse período, a de Frankl e Bettelheim em suas experiências no campo de concentração e a de Lewin na vivência dos preconceitos e no ostracismo, que caracterizaram aquele momento da história na Europa.

Mesmo tendo essa liberdade para desenvolverem suas teorias e "recomeçarem" a vida, é importante considerar que todos eles tiveram que se adaptar a um novo contexto, uma nova realidade e sociedade.

Lewin procurou compreender e abordar a vivência do seu sofrimento e do seu povo à luz da Psicologia Científica, visto que seu grupo étnico vivia em uma permanente insegurança na época pelas variações do clima político e o avanço do nazismo na Europa. Para ele, 0 grupo a que 0 individuo pertence constitui a base das percepções, ações e sentimentos, ou seja, é a base do grupo social que dá a configuração do individuo (LEWIN, 1948).

Já Frankl, da experiência que teve no campo de concentração derivou a importância da busca de sentido como fator essencial para a sobrevivência. Com base nisto, formulou sua teoria psicológica baseando-se no fato de que a busca de sentido é a principal força motivadora no ser humano. Portanto, afirmou que sempre existe a possibilidade do ser humano encontrar sentido nas dificuldades, no sofrimento e até na morte, considerando a liberdade e a responsabilidade da pessoa por suas ações (FRANKL, 1991).

Rudge (2009) aponta que as representações do trauma variam conforme o destino que a pessoa dê à experiência vivenciada. Mesmo deparando-se com situações difíceis de serem enfrentadas, os autores encontraram algum sentido em suas vivências e inclusive produziram teorias ou reafirmaram as teorias pré-existentes a partir de tais experiências. De acordo com Betthelheim (1991), este trabalho de elaboração possibilitou que sua personalidade não se desintegrasse, mantendo sua individualidade e autonomia, mesmo num contexto profundamente ameaçador.

De modo geral pode-se concluir que nos relatos e obras destes autores encontram-se tematizados os recursos pessoais, psicológicos e culturais que eles usaram para vivenciar ou superar o trauma. Todos eles enfrentaram o seu momento histórico de forma não 
alienada, tiveram uma posição ativa e tentaram indicar meios para superar os desafios presentes no mundo contemporâneo.

\section{Referências}

BARRERA, J. T. Los judíos hoy. Córdoba, Málaga, España: Ediciones El Almendro, 2005.

BETTELHEIM, B. O Coração informado: autonomia na era da massificação. Rio de Janeiro: Paz e Terra, 1985.

BETTELHEIM, B. Infopédia [Em linha]. Porto: Porto Editora, 20032009. Disponível em <http://www.infopedia.pt/\$bruno-bettelheim>. Acesso em: 24 out. 2009.

CANEPA, M. T.; CAMPOS, M. Apresentação teórica-vivencial: Porque o trauma acontece. Apresentado no XVII Congresso Internacional de Análise Bioenergética - Brasil-2003

FELDMANN, C. Edith Stein: Judia, atéia e monja. Bauru, SP: EDUSC, 2001.

FERREIRA-SANTOS, E. F.; SALDIVA, P. H. N.; KAUFMAN, A.; MASARO, G.; MAUAD, T.; SILVA, M. A. M. (2006). Avaliação da magnitude do transtorno de estresse em vítimas de seqüestro. Serviço de Psicoterapia do Instituto de Psiquiatria do Hospital das Clínicas da Faculdade de Medicina da Universidade de São Paulo.

FRANKL, V. E. Em busca de sentido: um psicólogo no campo de concentração. (Tradução: Walter O. Schlupp e Carlos C. Aveline). São Leopoldo, Editora Sinodal; Petrópolis, Editora Vozes, 1977/1991.

FREUD, S. Além do Princípio de Prazer. In: Obras completas. v. XVIII (1920). RJ: Imago, 1996.

FREUD, S. O mal-estar na civilização. In: Edição Standard Brasileira das Obras Psicológicas Completas de Sigmund Freud. v. XXI (1927-1931), p. 73-148. Rio de Janeiro: Imago Editora, 1930.

FULGENCIO, L. A noção de trauma em Freud e Winnicott. Natureza Humana, São Paulo, v. 6, n. 2, p. 255-270, jul.-dez. 2004.

GEOCITIES. II Guerra Mundial: A História do Holocausto. Disponível em: <http://www.geocities.com/Pentagon/Quarters/3415/holo.html>. Acesso em: 15/09/2009.

GUERREIRO, D.; BRITO, B.; BAPTISTA, J. L.; GALVÃO, F. Stresse Pós-traumático: os mecanismos do trauma. Departamento Universitário de Saúde Pública. Acta Medica Portuguesa, Lisboa, v. 20, p. 347-354, jan. 2007.

HALBWACHS, M. A memória coletiva (Tradução: B. Sidou), São Paulo: Centauro, 1968/2006.

LEWIN, K. Problemas de dinâmica de grupo. São Paulo: Editora Cultrix Ltda, 1948. 
MAILHIOT, G. B. Dinâmica e gênese dos grupos. São Paulo: Livraria Duas Cidades Ltda., 1991.

MASSIMI, M.; CAMPOS, R. H. F.; BROŽEK, J. Historiografia da Psicologia: Métodos. In: CAMPOS, R., H., F. (Org.). Historiografia da psicologia: pesquisa, formação, ensino. São Paulo: EDUC: ANPEPP, 1996.

PFRIMMER, T. Freud, leitor da Bíblia. Rio de Janeiro: Imago, 1994.

ROEHE, M. V. Revendo idéias de Viktor Frankl no centenário de seu nascimento. Revista PSICO, Porto Alegre, PUCRS, v. 36, n. 3, p. 311-314, set./dez. 2005.

RUDGE, A. M. Trauma. Rio de Janeiro: Ed. Jorge Zahar, 2009.

SILVEIRA, D. R.; MAHFOUD, M. Contribuições de Viktor Emil Frankl ao conceito de resiliência. Estudos de Psicologia. Campinas, v. 25, n. 4, dez./2008.

STEIN, E. Autobiografía: vida de uma família judía. In:

Obras completas I. Escritos autobiográficos y cartas. Monte Carmelo: El Carmen-Espiritualidad, p. 149-510, 1985.

VANDERBOS, G. R. (Org.). Dicionário de psicologia da APA. Tradução: BUENO, D.; VERONESE, M. A. V.; MONTEIRO, M. C. / Revisão Técnica: NUNES, M. L. T.; FRIZZO, G. B. Porto Alegre: Artmed, 2010.

XAUSA, I. A. M. A psicologia do sentido da vida. Petrópolis, Rio de Janeiro: Editora Vozes Ltda., 1986.

WERTHEIMER, M. Pesquisa história - Por quê? In: Brožek, J.; MASSIMI, M. (Org.). Historiografia da psicologia moderna: A Versão Brasileira. São Paulo: Edições Loyola, 1998.

\author{
Endereço para correspondência \\ Milena Callegari Cosentino \\ Campos da Universidade de São Paulo \\ Faculdade de Filosofia Ciências e Letras \\ Av. Bandeirantes, 3900. CEP: 14040-901. Ribeirão Preto, SP, Brasil \\ Endereço eletrônico: milena_callegari@yahoo.com.br \\ Marina Massimi \\ Campos da Universidade de São Paulo \\ Faculdade de Filosofia Ciências e Letras \\ Av. Bandeirantes, 3900. CEP: 14040-901. Ribeirão Preto, SP, Brasil \\ Endereço eletrônico: mmassimi3@yahoo.com
}

Recebido em: 18/01/2012

Reformulado em: 03/09/2012

Aceito para publicação em: 27/11/2012

Acompanhamento do processo editorial: Ana Maria Jacó Vilela

\footnotetext{
Notas

*Psicóloga, Mestranda em Psicologia pela Faculdade de Filosofia, Ciências e Letras de Ribeirão Preto.

**Professora Titular da Faculdade de Filosofia, Ciências e Letras de Ribeirão Preto. Departamento de Psicologia.
} 